\title{
On-Line Tools to Teach Chemical Engineering: Exploring Synergies
}

\author{
http://dx.doi.org/10.3991/ijep.v3iS1.2430 \\ M. G. Rasteiro ${ }^{1,2}$ \\ ${ }^{1}$ University of Coimbra Coimbra, Portugal \\ ${ }^{2} \mathrm{SPEE}$, Coimbra, Portugal
}

\begin{abstract}
This paper presents an open platform developed for the teaching of Chemical Processes stressing the synergistic effects of combining in the same platform different tools and also different subjects. The benefit for the students of the approach followed is discussed, namely on what concerns knowledge integration. The results of a questionnaire which has been filled by the students during the last four school years are presented. Access to the platform is continuously monitored and will be reported here.
\end{abstract}

Index Terms-On-line labs; Chemical Processes; e-learning, simulators

\section{INTRODUCTION}

Presently, one of the main concerns of educators is to lead their students to develop analytic capabilities and autonomous and critical thinking. This is, of course, of maximum importance in the case of Engineering, since engineers are required during their professional life to integrate complementary knowledge and to work in multidisciplinary teams. In addition, engineering students need to develop a practical approach to the subjects addressed, in parallel to the scientific background.

These facts have been acting as driving-forces to motivate engineering educators to develop new teaching methodologies. In the field of Chemical Engineering online laboratories have been under development since the 1990s. This is the case of the on-line labs of the University of Tennessee, USA (http://chem.engr.utc.edu/) or the work developed in the Massachusetts Institute of Technology,

USA

(http://groups.csail.mit.edu/mac/projects/icampus/projects/ ilab.html) and the work of the University of Cambridge, UK (http://www.cambridge-mit.org/project), as a result of the Cambridge-MIT partnership program. A review paper by Kadiyala and Crynes [1] provides an overview of the effectiveness of information technologies in education. In fact, these tools facilitate the development of additional teaching strategies for simulation, demonstration, experimentation and operation, to mention just a few, contributing to engage students and to developing a truly active learning attitude [2]. This leads us to conclude that by using different resources the dynamics in the classes can increase.

However, the web laboratories and simulators mentioned above are limited in the sense that each of them only deals with a specific subject, for instance, transport phenomena, unit operations or control [3-6].

In the Chemical Engineering Department of the University of Coimbra the strategy was to develop a web portal for the teaching of Chemical Engineering which focuses on a wide range of subjects and brings together multime- dia libraries (theoretical and basic information), simulators and on-line experiments, both presented as videos and remote control experiments [7]. This platform was developed as a result of a cooperation between the universities of Coimbra and Porto, in Portugal.

\section{LABVIRTUAL}

The integration of Chemical Engineering subjects was our uppermost objective but other learning outcomes can be achieved with this multipurpose portal:

- $\quad$ by dealing with more realistic problems (open-ended and multidisciplinary), simulators help obtain solutions within a reasonable timescale in class or at home, and train critical and creative thinking while also preparing students to optimize process designs.

- in mini-projects, students can improve existing programs, which can then be introduced back into the platform with two purposes: developing computer programming skills, establishing input/output relationships and enhancing structured thinking.

- virtual labs complement real labs: the latter give students "hands-on" exposure, where they can feel the equipment and how it operates; the former help prepare the student to be more productive in the real laboratory.

- the students are encouraged to use the simulators section as a guide for the treatment of the data collected in the lab, so that they realize better how and why to treat the experimental data in a certain way, and how to withdraw the correct and most important information from it.

- the students can experience an industrial control room based on LabVIEW ${ }^{\circledR}$ computer interfaces; they can also explore operating scenarios which might not be easily or economically studied with real equipment.

The Bologna Process suggests a reduction of formal lecture hours and stresses the importance of autonomous work. Thus, this type of approaches have assumed an increasing importance to help students in their learning process. The portal presented here, LABVIRTUAL (http://labvirtual.eq.uc.pt), directed to the teaching of Chemical Processes, which was made available on-line for the first time in the school year 2009/10, is an example of one of such tools. The portal was developed in Portuguese because it is aimed for Portuguese-speaking students, including those from African, Latin America and Asian countries, with the objective of strengthening links with universities from those countries, contributing to the increase of the already existing students' mobility. 


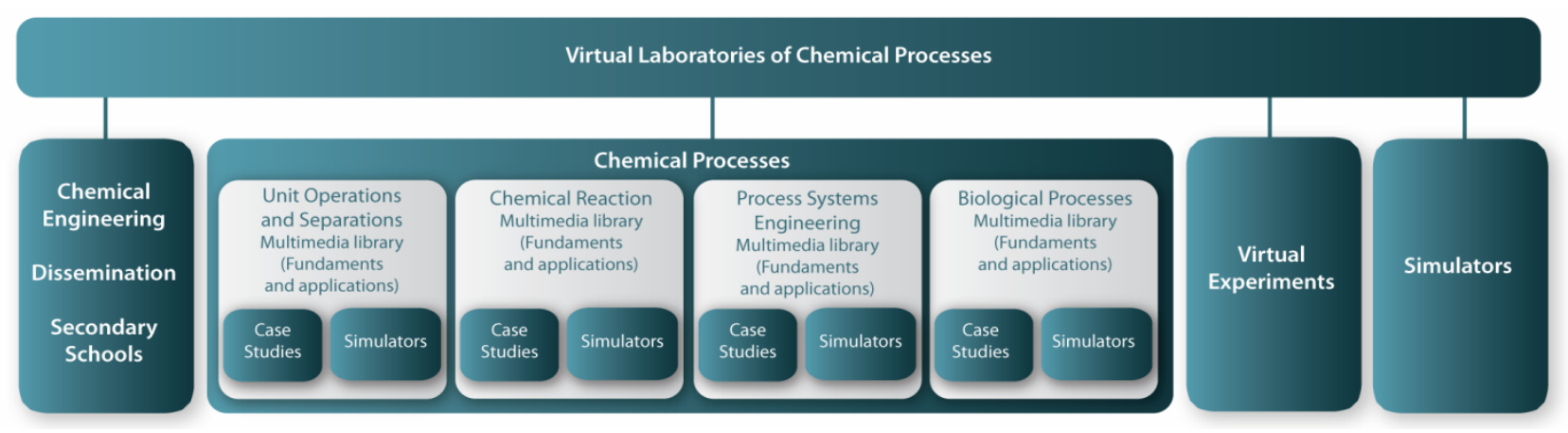

Figure 1. Scheme of the platform LABVIRTUAL.

The portal includes four different areas: Chemical Engineering, Chemical Processes, Virtual Experiments and Simulators. The Chemical Engineering area addresses the general public, enabling students from the basic education levels to obtain information on what Chemical Engineering is about, Chemical Engineering History, new developments in Chemical Engineering and also new trends in Chemical Engineering Education. The home page includes a section directed only to secondary school students, where engineering problems involving concepts already taught at the secondary school level are presented.

The Chemical Processes area comprises four sections: Unit Operations and Separations, Chemical Reaction, Process Systems Engineering and Biological Processes, as shown in Fig. 1. These sections deal with chemical/biochemical processes and present fundamental concepts and applications aimed at leading the students to understand, for instance, how different operating conditions result in different process designs, or which alternatives are available for a certain process. Moreover, each section includes case studies illustrating some of the features of the applications developed.

The case studies were constructed in order to guide the students in the use of the simulators, namely leading them to understand the choice of the most adequate models to perform the design of the process under study, as well as the limitations of each model. The Simulators section comprises so far 20 different simulators related to the different processes. In some modules, a database of physicochemical properties for a limited set of chemicals is available and simulations can be performed for different feed mixtures. Modularity is also explored in several cases, with process simulators accommodating several more fundamental modules. For instance, there is an autonomous module of vapor-liquid equilibrium to perform calculations such as the boiling point of a liquid mixture, which is also invoked within the distillation module, where large scale equipment to separate a liquid mixture is simulated.

The Virtual Experiments section deals both with the laboratory visualization of the basic phenomena related to the processes presented in the other sections, and with the remote monitoring of laboratory experiments. Additionally, these visualizations will also be used to help students to better prepare their lab classes, in order to take the maximum benefit from them.

These complementary tools lead the students to a better understanding of the processes addressed which, in fact, correspond to different courses from the Chemical Engineering curricula at the University of Coimbra. They can perceive better how chemical/biochemical processes are dependent on a few basic mechanisms, which are visualized and discussed in the videos available in the portal or on the real lab experiments. Moreover, the multifunctional web platform presented allows taking advantage from the combination, in a single platform, of the coexistence of teaching tools for a broad range of Chemical Processes, which motivates knowledge integration. By using the platform the students should be able to: understand and relate basic concepts and principles associated to each process; establish analogies between different processes; understand, apply and know the limitations of the modeling methodologies commonly used to interpret and troubleshooting industrial problems; have an idea of the impact of operational parameters on equipment design and cost. This makes it easier to introduce the students to more practical and realistic approaches to Chemical Engineering problems.

\section{WeB METHOdOLOGIES}

The Web infrastructure of the Virtual Laboratories of Chemical Processes is based on standard open-source software. This approach allows similar functionalities to existing commercial software, with good flexibility for the specific needs of the Portal. A Virtual Server is used that can integrate contents from various sources and present these contents in a consistent way to the user. Most of the materials available are stored in a Content Management System (CMS), for flexibility and to simplify the inclusion of new material. Joomla! was used for this task. Predefined presentation templates simplify the addition of new contents and the management of several kinds of information, such as texts, images, forms, lists, etc.

The integration of simulators and data acquisition systems with the Web portal is a critical point. The simulations are entirely run on the server and the user just needs a regular browser to access and interact with the platform. Since, as referred, the CMS used allows the construction of customized templates for the presentation of information, the integration with the simulators is made by developing forms to visualize and manage real-time data, and for the insertion of input parameters used by the simulators to run calculations and for presentation of the results to the users. This layer validates the user input and executes a system call to autonomous simulation codes. As a result of a successful simulation, graphical and numerical results can be returned, to be displayed on the web page. The communication between the computational applications and the web platform itself is done through a simulation gateway using a CGI (Common Gateway Interface) protocol. 
Simulators were programmed having special attention to the purposes of the Portal:

- the use of calculation methodologies and concepts given in classroom providing a better integration between the fundaments and applications;

- the support of the user through helps that provide error and warning messages in the case of unfeasible situations or impossible chemical/physical conditions;

- supply flexible programs with a fair number of options that allow the solution of more realistic and open-ended problems;

- $\quad$ to promote teamwork, critical and creative thinking by providing open-code programs to the students instead of black-box programs. The student is challenged with individual and team mini-projects to create or improve existing codes.

\section{ASSESSING THE USE OF THE PlatForm}

The LABVIRTUAL platform is being used, since 2009, in the Chemical Engineering curricula of the University of Coimbra in several courses, such as Transport Phenomena, Chemical Thermodynamics, Reaction Engineering, Process Separations, Control Engineering and Biological Processes, all courses either from the $1^{\text {st }}$ or $2^{\text {nd }}$ cycles in Chemical Engineering, according to the Bologna scheme (see Rasteiro et al. 2009 [7]). Depending on the characteristics of the course, the use of the platform can be optional or compulsory and the students have been using it not only for autonomous study but also to solve homework assignments. In some of the courses the students are also required to apply their programming skills: for instance, in mini-projects, students have to modify the current simulators for other, more complex, applications and/or conditions.

According to the philosophy behind its construction, the web site can be used in the classroom to illustrate the design and operation of process equipment, for instance to show the influence of operating conditions, feed characteristics, etc. on the design outcome, or even to evaluate the validity of different models used for the design. The teacher can, as well, use the simulators to illustrate the influence of fundamental concepts on the design of process equipment. Simulators help obtain solutions within a reasonable timescale and allow training critical and creative thinking. In fact, one of the main objectives of the Portal is to provide a practical approach for chemical processes, to the students, which are guided to evaluate the influence of operating conditions on equipment design, analyze the results obtained and compare them with those in the literature.

After this first contact with the facilities of the platform in a certain course, the student can go on using the site on her/his own, taking advantage of the case studies included there, which guide them on the use of the simulators, and help in illustrating the phenomena described in the fundaments section, as well as to solve new problems. Students are supervised by the teacher in their home assignments, discussing with them the results obtained. Furthermore, the student can use the available tools to solve other assignments (design problems) or even, at a later stage, use modules of the simulators (which will be made available to them) to build more complex programs required to deal with more elaborated design problems.
In several sections of the Portal the basic concepts of Chemical Engineering such as Thermodynamics, Heat and Mass Transfer and Chemical Kinetics, which are treated autonomously, are later recalled in those sections dealing with process and equipment design. In this way, the students are led to understand better the basic mechanisms behind the different chemical processes, integrating basic concepts with the design and selection of process equipment.

Moreover, the processes selected for inclusion in the portal are quite typical of Chemical Industries and also equally important for Bioprocesses. Furthermore, the strategy behind the construction of the platform is, for all the processes considered, to guide the student from the easiest to more complex approaches and models.

In the case of the Process systems Engineering (PSE) section, which develops methodologies for systematic decision-making in chemical processes, besides the section on instrumentation and sensors, there is a section directed to control theory and applications, dealing with a range of different process control strategies. Another section addresses the use of methodologies of process integration and optimization, in the context of rationalization of energy and utility usage in the process industries. A simulator is provided, for fast determination of predefined efficiency targets, once the basic concepts are mastered.

The main philosophy behind the construction of the whole platform is to lead the student to be able to integrate a large range of concepts of chemical engineering, opposing the normal tendency for fragmented learning and knowledge.

Another important feature of these methodologies (web tools) is the possibility of their use in lifelong learning, in particularly the facilities of the multimedia libraries and the process simulators. Though at the University of Coimbra we have not been exploring this feature, so far, it is believed, based on the extensive access the platform has been receiving monthly (since it was made available online in 2009 there has been an average of 30000 visits/month, largely exceeding the universe of our students) that the platform is already being used for knowledge update.

Since the Portal was first introduced in the teaching of several Chemical Engineering courses from the Chemical Engineering Masters degree from the University of Coimbra (2009), we have been monitoring the use of the Portal by the students and their opinion about the tools available, asking them to fill out an anonymous questionnaire in each course. The questionnaire is very similar for the different courses, only with slight variations. Fig. 2 (a) presents the questionnaire which is being used in the courses of "Separation processes I and II" and "Reaction Engineering". The questions address different aspects of the learning experience, students frequency and purpose of use, which facilities they have used, as well as the evaluation of the interface and of the structure of the portal.

Here, as an example, the results for the students responses to the questionnaire handled in the Process Separations course are shown in Figure 2 (b), for the four last editions (since 2009), corresponding to a total of 140 respondents. 
SPECIAL FOCUS PAPER

ON-LiNE TOOLS TO TEACH CHEMICAL ENGINEERING: EXPLORING SYNERGIES

\begin{tabular}{|c|c|}
\hline $\begin{array}{l}\text { I. Have you used the Virtual Laboratories? } \\
\text { Yes } \square \quad \text { No } \square \\
\text { 2. Have you used the Virtual Laboratories as a support to your study? } \\
\text { Yes } \square \quad \text { No } \square \\
\text { 3. Have you used the Virtual Laboratories to do design projects? } \\
\text { Yes } \square \quad \text { No } \square \\
\text { 4. What is your appreciation of the Virtual Laboratories } \\
\text { (section of Unit Operations and Separation Processes)? } \\
\begin{array}{llll}\text { 4.1: A) Useless } & \text { B) Rather useful } & \text { C) Useful } & \text { D) Very useful } \\
\text { 4.2: A) Badly structured } & \text { B) Well structured } & \text { C) Very well structured }\end{array}\end{array}$ & 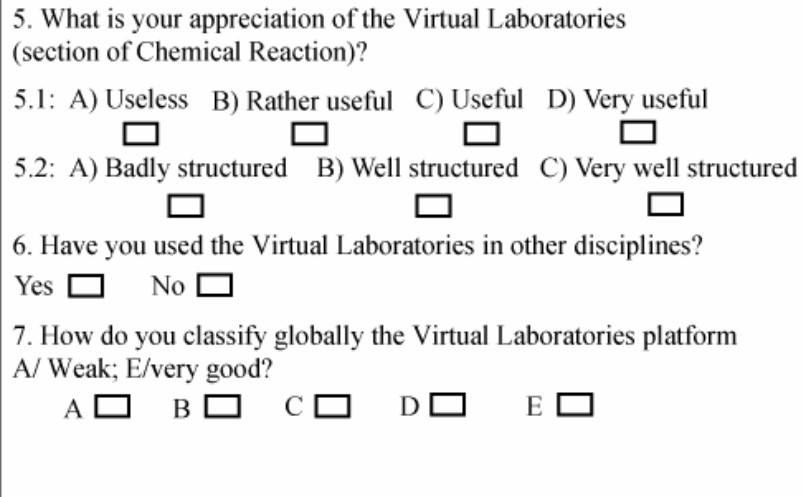 \\
\hline
\end{tabular}

(a)

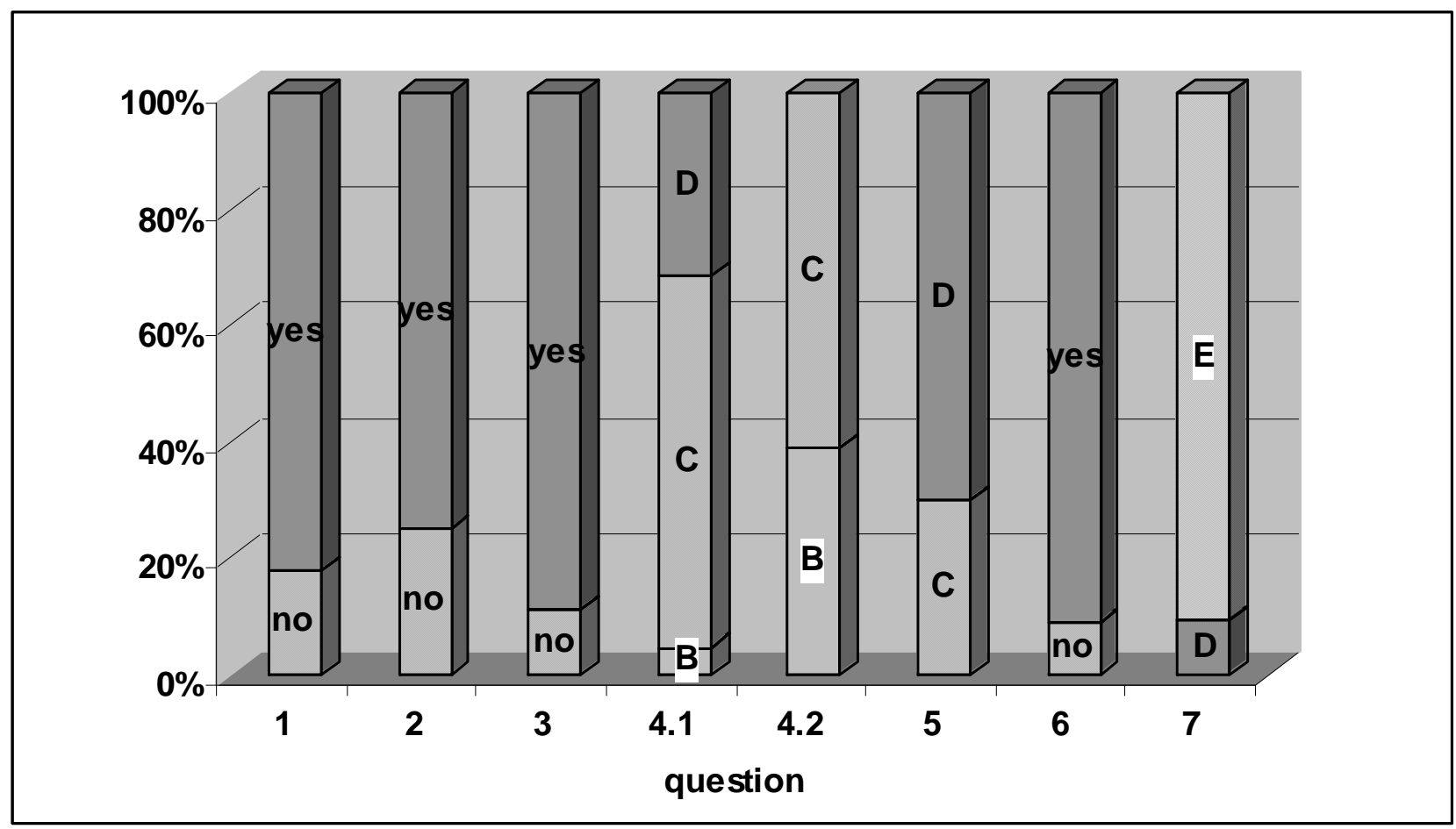

(b)

Figure 2. Assessment of the platform: (a) questionnaire; (b) results.

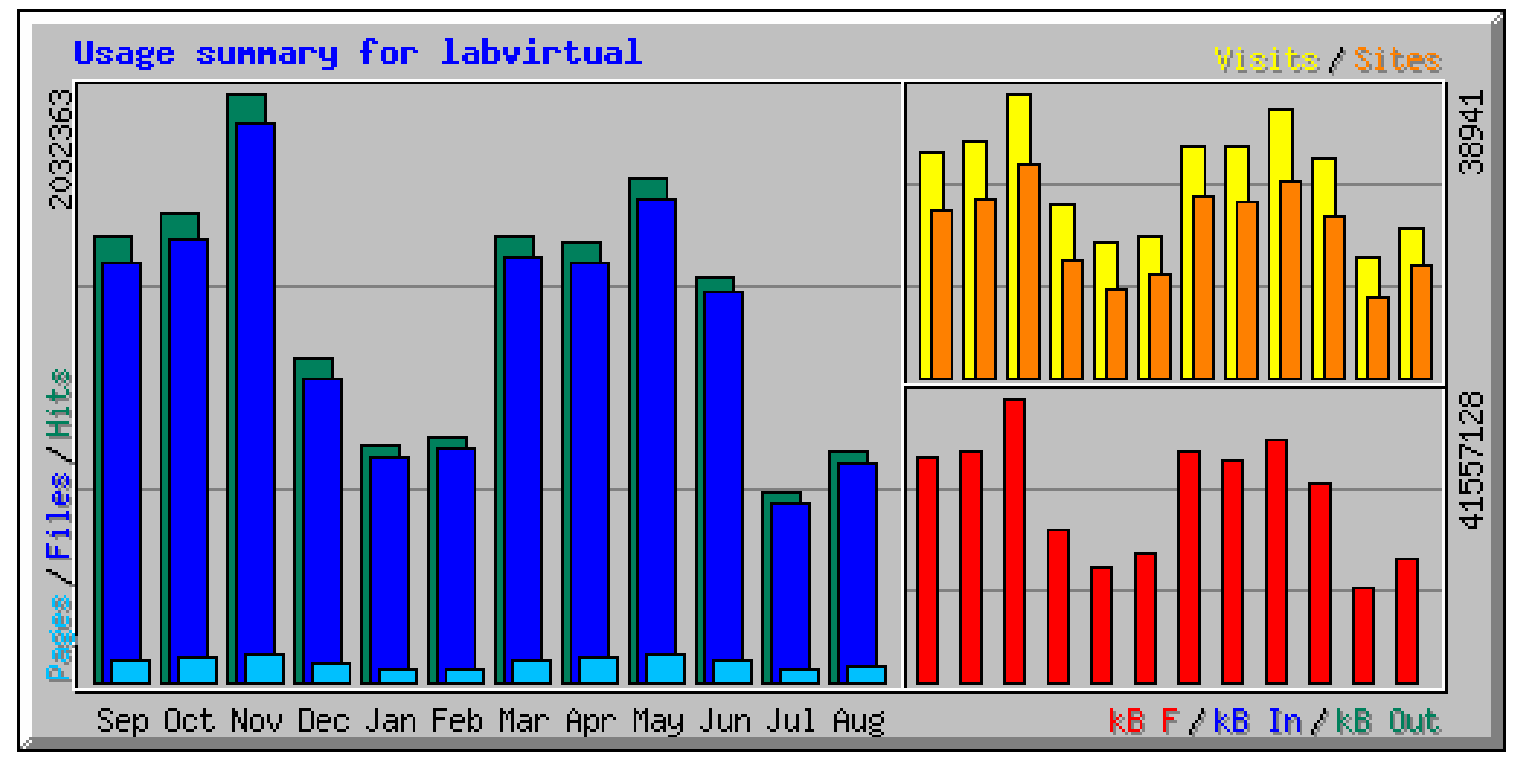

Figure 3. Statistics of accesses to LABVIRTUAL in 20111/12 


\section{SPECIAL FOCUS PAPER \\ ON-LiNE TOOLS TO TEACH CHEMICAL ENGINEERING: EXPLORING SYNERGIES}

The students response was, as a whole, very positive: $82 \%$ had used the platform in the Process Separations I discipline and about $91 \%$ had also used it in other subjects. Moreover, it was observed that the majority of the students had used LABVIRTUAL as a support to their study, with most of them using the platform several times. Another good point was that a vast majority of the students considered the Unit Operations and Separation Processes area of the platform as useful, very easy to use and very well structured. Globally, LABVIRTUAL achieved a very good rate among the students enquired.

At a different level, LABVIRTUAL has been receiving a very good acceptance from the public, in general, with an average of 30000 visits per month, from which about $65 \%$ are from foreign Portuguese-speaking countries like Brazil, Angola and Mozambique. Fig. 3 shows the statistics of visits for 2011/12. As referred previously, we have information that, at least some areas of this teaching tool are being used in a number of universities from Portuguese speaking countries, especially from Brazil, as well as in Brazilian companies like PETROBRÁS.

\section{CONCLUSIONS}

In general it is now commonly accepted that web tools are important complementary instruments for the teaching and learning process. They can be accessed with maximum flexibility, from any place at any time, and contribute to the students autonomy. The experience of using this multi-purpose platform, during four school years, has been evaluated very positively by the students, based on the questionnaire which is handed yearly to the students in each course. Additionally, this site is intended to be a dynamic Web Portal open to share experiences with other schools and educators.

Moreover, the features described contribute to give the student an integrated approach to Chemical Processes, leading them to an easier integration of knowledge addressed in different courses. Furthermore, the teacher can use these tools in the classroom, namely the simulators, to illustrate in an easy way several concepts, for instance how operating conditions influence the design of process equipment, or to discuss with the students how the choice of one or another model can influence the final design, depending on the characteristics of the system. This makes it easier to introduce the students to more practical and realistic approaches to Chemical Engineering problems.
The experience of both teachers and students shows that the tools available allow addressing more realistic, open-ended and multidisciplinary problems, helping in training critical and creative thinking and in improving students' autonomy.

\section{ACKNOWLEDGMENT}

We would like to acknowledge the sponsorship from POSC (Programa Operacional da Sociedade de Conhecimento, Portugal, contract 743/4.2/C/REG) which enabled the development of the platform LABVIRUAL as well as to the whole team involved in its development (15 faculty members and 5 grant holders).

\section{REFERENCES}

[1] M. Kadiyala and B. Crynes, "A review of literature oneffectiveness of use of information technology in education", J Eng Ed, 89 (2), pp. 177-189, 2000.

[2] R. M. Felder, "Teaching engineering in the 21 st century with a 12th-century teaching model: how bright is that?", Chem Eng. Ed, 40 (2), pp. 110-113, 2006.

[3] S. J. Streicher, K. West, D. M. Fraser, J. M. Case and C. Linder, "Learning through simulation - student engagement", Chem. Eng. Ed., 39 (4), pp. 288-301, 2005.

[4] A. Selmer, M. Kraft, R. Moros and C. K. Colton, "Weblabs in chemical engineering education", Trans IChemE, part D, Educ Chem Eng, 2, pp. 38-45, 2007. http://dx.doi.org/10.1205/ece06018

[5] S. Vaidyanath, J. Williams, M. Hilliard, and T. Wiesner, "The

[6] development and deployment of a virtual unit ops laboratory", Chem Eng Ed, 41(2), pp. 144-152, 2007.

[7] J. Henry and H. M. Schaedel, "International co-operation in control engineering education using online experiments", Eur J Eng Ed, 30 (2), pp. 265-274, 2005. http://dx.doi.org/10.1080/ $\underline{03043790410001065678}$

[8] M. G. Rasteiro, L. M. Ferreira, J. C. Teixeira, F. P. Bernardo, M. G. Carvalho, A. Ferreira, R. Q. Ferreira, F. P. Garcia, C. G. Baptista, N. M. Oliveira, M. M. Quina, L. O. Santos, P. A. Saraiva, A. M. Mendes, F. M. Magalhães, A. S. Almeida, J. Granjo, M. Ascenso, R. M. Bastos, R. Borges, "LABVIRTUAL a virtual platform to teach chemical processes", Education for Chemical Engineers, 4 (1), pp. e9-19, 2009. http://dx.doi.org/ 10.1016/j.ece.2009.02.001

\section{AUTHOR}

M. G. Rasteiro is with the Chemical Engineering Department, University of Coimbra and with SPEE, Coimbra, Portugal.

This article is an extended and modified version of a paper presented at the IGIP2012 conference, held 26 - 28 September 2012, in Villach, Austria. Received 9 December 2012. Published as resubmitted by the author 28 January 2013. 